\title{
Aminopeptidase inhibitor bestatin stimulates microvascular endothelial cell invasion in a fibrin matrix
}

\author{
Yvette van Hensbergen', Henk J. Broxterman ',4, Erna Peters², Sareena Rana', Yvonne W. Elderkamp', \\ Victor W. M. van Hinsbergh", ${ }^{2}$, Pieter Koolwijk ${ }^{2}$ \\ 'Department of Medical Oncology, VU University Medical Center, Amsterdam, The Netherlands \\ ${ }^{2}$ Gaubius Laboratory, TNO-PG, The Netherlands \\ ${ }^{3}$ Department of Physiology, Institute for Cardiovascular Research, VU University Medical Center, Amsterdam, The Netherlands
}

\section{Summary}

The aminopeptidase inhibitor bestatin has been shown to have anti-angiogenic effects in a number of model systems. These effects are thought to result from inhibition of $\mathrm{CDI} 3$ activity. Because tumor angiogenesis can evolve in a fibrin-rich stroma matrix we have studied for the first time the effects of bestatin on microvascular endothelial capillary-like tube formation in a fibrin matrix. Bestatin enhanced the formation of capillary-like tubes dose-dependently. Its effects were apparent at $8 \mu \mathrm{M}$; the increase was 3.7-fold at $125 \mu \mathrm{M}$; while high concentrations $(>250 \mu \mathrm{M})$, that were shown to have anti-angiogenic effects in other systems, caused extensive matrix degradation. Specific CDI3-blocking antibodies WMI5 and MY-7, and the aminopep- tidase inhibitors amastatin and actinonin also enhanced capillary-like tube formation (maximally I.5-fold), but these effects did not reach statistical significance. The effect of bestatin was not due to a change in UPAR availability because the relative involvement of the u-PA/u-PAR activity was not altered by bestatin. In view of the present findings we hypothesize that aminopeptidases other than $\mathrm{CDI} 3$ predominantly contribute to the observed pro-angiogenic effect of bestatin in a fibrin matrix. The identification of this novel effect of bestatin is important in the light of the proposed use of bestatin as antiangiogenic and/or anti-tumor agent.

\section{Keywords}

Bestatin, CDI3, angiogenesis, fibrin, u-PAR

Thromb Haemost 2003; 90: $921-9$

\section{Introduction}

Angiogenesis, the process of new blood vessel formation from existing vasculature, is essential for the growth and metastasis of many solid tumors. The angiogenic cascade is a highly organized process in which various steps occur sequentially, including activation of the endothelial cells, degradation of the basement membrane, migration and proliferation of the endothelial cells, the formation of a tubular network and eventually the development of a newly stabilized microvessel. Inhibition of the angiogenic process has become an important strategy for the treatment of tumors (reviewed by Carmeliet and Jain (1)).

A fibrinous exudate is formed when blood vessels become permeable (e.g. after stimulation with VEGF) and plasma leaks out and is often found in the provisional matrix. This temporary fibrin deposit provides a matrix into which endothelial cells can migrate and form new microvessels $(2,3)$. The invasion of endothelial cells into the fibrin matrix requires fibrinolytic 
activity, which depends primarily on cell-bound urokinase-type plasminogen activator ( $\mathrm{u}-\mathrm{PA}$ ) and plasmin activities. To that end, u-PA is bound to a cellular receptor, the u-PA receptor (u-PAR, CD87), on which it is activated from its pro-form. Bound to u-PAR, u-PA exerts local proteolytic activity and converts cell-bound plasminogen into plasmin $(4,5)$. Mutual interactions between matrix metalloproteinase (MMP)-like activities and the u-PA/plasmin-system occur (6). Several pro-MMPs can be activated by plasmin (7) and several MMPs are able to inactivate the u-PAR by removing the D1 domain from the receptor $(8,9)$. In specific conditions, membrane-type metalloproteases (MT1-MMP) can also contribute to angiogenesis in a fibrin matrix by exerting local proteolytic activity (10-12) .

Bestatin is a small dipeptide that was discovered more than 25 years ago in the medium of Streptomyces olivoreticuli (13). Bestatin effectively inhibits cell surface aminopeptidase activities, of which CD13/Aminopeptidase N (EC 3.4.11.2; CD13) appears to be the major target. Other cell surface peptidases that can be inhibited by bestatin are aminopeptidase B and cystinyl aminopeptidase (reviewed by Scornik and Botbol (14)). As an aminopeptidase inhibitor, bestatin has been reported to exert diverse anti-tumor and immunomodulatory activities $(15,16)$.

Only recently was it shown that bestatin also exhibits antiangiogenic effects both in vitro and in vivo $(17,18)$. So far, the membrane-bound protein CD13 is the only target identified for the anti-angiogenic properties of bestatin. Recent studies have shown that CD13 is specifically expressed on tumor angiogenic vessels and not on normal vasculature (18). One mechanism for the upregulation of CD13 expression seems to involve the activation of the Ras and Erk signaling pathways upon stimulation of endothelial cells with angiogenic growth factors, such as bFGF (19). In addition, specific inhibition of the CD13 activity with monoclonal antibodies was shown to reduce angiogenesis in vitro and in vivo $(17,18,20)$. Although $\mathrm{CD} 13$ has been identified as a regulator of angiogenesis, the mechanism by which CD13 exerts its effect on neovascularization is still undetermined. Until now, no specific substrates for CD13 that are candidates for its angiogenic effect have been identified. Possibly, the soluble form of CD13, that was recently found to be increased in the plasma from cancer patients, adds to the angiogenic effect of CD13 (21).

Considering the lack of knowledge on the role of aminopeptidases in general and CD13 in particular in angiogenesis, we decided to study the effect of bestatin in a defined fibrin matrix. In this study we show that in contrast to the described antiangiogenic effects, in a fibrin matrix bestatin exhibits proangiogenic properties at relatively low concentrations. In addition, our results with the CD13 inhibiting antibodies and with two additional synthetic aminopeptidase inhibitors suggested that the pro-angiogenic activities of bestatin are not exclusively the result of inhibition of CD13 activity.

\section{Materials and methods}

\section{Materials}

Bestatin, actinonin, and amastatin were purchased from Sigma. The anti-CD13 antibodies were obtained from Pharmingen (WM15), DAKO (WM47) and Coulter Clone (MY-7). The antiu-PAR antibody (H2) was obtained from Dr. U. Weidle (Boehringer Mannheim, Penzberg, Germany).

\section{Cell culture}

Human foreskin microvascular endothelial cells (hMVEC) were isolated and grown as described by Koolwijk et al. (4). The cells were cultured on gelatin coated culture dishes in M199 supplemented with $20 \mathrm{mM}$ HEPES, $10 \%$ human serum (HS), 10\% new born calf serum (NBCS), $150 \mu \mathrm{g} / \mathrm{ml}$ crude endothelial cell growth factor (ECGF), $5 \mathrm{IU} / \mathrm{ml}$ heparin, $2 \mathrm{mM} \mathrm{L}$-glutamine, $200 \mu \mathrm{g} / \mathrm{ml}$ penicillin and $200 \mu \mathrm{g} / \mathrm{ml}$ streptomycin. The cells were used in passage 9 to 11. Human umbilical cord vein endothelial cells (HUVEC) were isolated and cultured from single umbilical cords essentially according to procedures described extensively before (22). HUVECs were cultured in gelatin coated culture flasks (Costar) in M199 medium (Gibco) containing $10 \% \mathrm{HS}, 10 \%$ fetal calf serum (FCS) (Gibco), $5 \mathrm{IU} / \mathrm{ml}$ heparin, $200 \mu \mathrm{g} / \mathrm{ml}$ penicillin and $200 \mu \mathrm{g} / \mathrm{ml}$ streptomycin, $290 \mathrm{mg} / \mathrm{ml} \mathrm{L}-$ glutamine and $50 \mu \mathrm{g} / \mathrm{ml} \mathrm{ECGF}$, isolated from bovine brain (22). HUVECs were used for experiments in passage 3 to 5 . All cells were cultured at $37^{\circ} \mathrm{C}$ in $5 \% \mathrm{CO}_{2}$. Growth inhibition was measured in a standard MTT-assay in 96-well plates and 50\% inhibition of cell growth is expressed as $\mathrm{IC}_{50}$.

\section{CDI3 and integrin detection in endothelial cells}

hMVECs were cultured in standard medium with or without bFGF (10 ng/ml) and TNF $\alpha(10 \mathrm{ng} / \mathrm{ml})$ for $72 \mathrm{~h}$. Total RNA was isolated for analysis. For the reverse transcriptase-polymerase chain reaction (RT-PCR), the following primers specific for CD13 were used: (forward) 5'-GTAATACGACTCACTATAGGGCCAGGGGCCTGTACGTTTTTA-3', (reversed) 5'A AT TAA C C C T C A C TA A A G GGC CA C C A GC T CAGTCTTGTCA-3', for GAPDH the following primers were used: (forward) 5'-ACCACAGTCCATGCCATCAC-3', (reversed) 5'-TCCACCACCCTGTTGCTGTA-3'. Samples were denaturated for $5 \mathrm{~min}$ at $94^{\circ} \mathrm{C}$; subsequently the amplification was performed in 36 cycles of $30 \mathrm{sec}$ at $94^{\circ} \mathrm{C}, 30 \mathrm{sec}$ $58^{\circ} \mathrm{C}$, and $30 \mathrm{sec} 72^{\circ} \mathrm{C}$, followed by $5 \mathrm{~min}$ at $72^{\circ} \mathrm{C}$.

Real-time (Light cycler) PCR was performed with $2 \mu \mathrm{l}$ cDNA in $2 \mu \mathrm{l}$ LightCycler-FastStart DNA Master SYBR Green (Roche), $3.3 \mathrm{mM} \mathrm{MgCl}_{2}$ and $0.5 \mathrm{mM}$ primers in a total volume of $20 \mu$, in a rapid PCR amplification (initial denaturation step at $95^{\circ} \mathrm{C}$ for $10 \mathrm{~min}$, followed by 45 cycles of $95^{\circ} \mathrm{C}$ for $0 \mathrm{sec}$, $54^{\circ} \mathrm{C}$ for $20 \mathrm{sec}$ and $72^{\circ} \mathrm{C}$ for $18 \mathrm{sec}$ ). The specificity of the PCR-product was verified with a melting curve and on gel. 
Relative mRNA in Arbitrary Units was calculated by ( $\mathrm{E}^{-\mathrm{Cp} \text { target }}$ gene $) /\left(\mathrm{E}^{-\mathrm{Cp} \text { reference gene }}\right)$; in which $\mathrm{E}=$ efficiency $(\mathrm{GAPDH}: 1.77$ and $\mathrm{CD} 13: 1.89)$ and $\mathrm{Cp}=$ crossing point.

For FACS analysis of CD13 expression, the cells were grown under standard conditions until $80 \%$ confluence. For analysis of integrin expression, cells of $50-80 \%$ confluence were cultured for $24 \mathrm{~h}$. in M199 supplemented with $10 \% \mathrm{HS}$, $10 \%$ NBCS, and penicillin/streptomycin (100 U/ml). Subsequently, $10 \mathrm{ng} / \mathrm{ml}$ TNF $\alpha$ (ICN Biomedicals) and $10 \mathrm{ng} / \mathrm{ml}$ bFGF with or without $125 \mu \mathrm{M}$ bestatin was added to the cells for 72 hours. Thereafter, $1 \times 10^{5}$ cells were incubated at room temperature for $30 \mathrm{~min}$ with FITC-conjugated anti-human CD13 monoclonal antibody WM-47 (5 $\mu \mathrm{g} / \mathrm{ml}$; DAKO) or FITCconjugated mouse-IgG1 (DAKO), and for integrin expression $60 \mathrm{~min}$ at room temperature with $5 \mu \mathrm{g} / \mathrm{ml}$ of the primary mouse antibodies: control IgG (DAKO), CD29 ( $\beta_{1}$; clone Lia 1/2), CD49eVLA5 $\left(\alpha_{5}\right.$; clone SAM-1) and CD51 $\left(\alpha_{v}\right.$; clone AMF-7) (all Immunotech, France), and mouse $\alpha$ human integrin $\alpha_{v} \beta_{3}$ (clone LM609; Chemicon, Temucula, CA), followed by a 30 minutes incubation at room temperature with rabbit-antimouse-IgG-FITC (1:200; DAKO, Denmark). Subsequently, the cells were washed and analyzed on a FACS Calibur flow cytometer (Becton Dickinson).

\section{Morphogenesis on matrigel}

HUVECs were harvested and resuspended in M199 supplemented with $0.5 \%$ serum and $1 \mathrm{ng} / \mathrm{ml} \mathrm{VEGF}$ at a concentration of $1.5 \times 10^{4}$ cells $/ \mathrm{ml}$. $1.5 \times 10^{3}$ cells were plated in a 96 -wells plate coated with $0.5 \mathrm{mg} / 50 \mu \mathrm{l}$ Matrigel (Becton Dickinson). Bestatin and WM-15 were added to the medium. After 18 h., network formation was examined under an inverted microscope. Images were taken with a video camera attached to a computer with Leica Q500MC/QWin-software. A grid was used to count the number of tube like structures on top of the Matrigel, 5 images per well were analyzed.

\section{Matrigel invasion assay}

The Matrigel invasion assay was performed in a 24-wells plate transwell system (Falcon). Filters with $8 \mu \mathrm{m}$ pore size (HTS Fluoroblok Insert, Becton Dickinson) were coated on the lower side with gelatin $(1 \% \mathrm{w} / \mathrm{v})$ for $2 \mathrm{~h}$. and washed with PBS before coating the upper side of the filter with Matrigel $(5 \mu \mathrm{g} /$ filter, ECM gel, Sigma). M199 containing 0.1\% BSA (Sigma) and VEGF $(25 \mathrm{ng} / \mathrm{ml})$ was added to the lower compartment. HUVECs were harvested and resuspended in M199 with $0.1 \%$ BSA and $2 \times 10^{5}$ cells were added to the upper compartment. The inhibitors were added to both compartments. The cells were allowed to invade for 18 hours at $37^{\circ} \mathrm{C}$ and $5 \%$ $\mathrm{CO}_{2}$. Invasion was quantified by incubating the cells in the lower compartment with $5 \mu \mathrm{M}$ Calcein-AM (Molecular Probes) at $37^{\circ} \mathrm{C}$, during the final $30 \mathrm{~min}$ of the assay. Fluorescence in the lower compartment was measured in a Spectrafluor multi- plate reader (Tecan, Salzburg, Austria) $\left(\lambda_{\mathrm{exc}}\right.$ of $492 \mathrm{~nm}$ and $\lambda_{\mathrm{em}}$ of $535 \mathrm{~nm})$.

\section{Fibrin gel assay}

Human fibrin matrices were prepared by the addition of $0.1 \mathrm{U} / \mathrm{ml}$ thrombin (Organon Technika, Boxtel, The Netherlands) to a mixture of $2.5 \mathrm{U} / \mathrm{ml}$ factor XIII (Dr. H. Boeder and Dr. P. Kappus, Centeon Pharma GmbH, Marburg, Germany), $2 \mathrm{mg} / \mathrm{ml}$ fibrinogen (Chromogenix AB, Sweden), $2 \mathrm{mg} / \mathrm{ml} \mathrm{Na-}$ citrate, $0.8 \mathrm{mg} / \mathrm{ml} \mathrm{NaCl}$ and $3 \mu \mathrm{g} / \mathrm{ml}$ plasminogen in M199 medium (pH 7.4) (final concentrations). A total of $100 \mu \mathrm{l}$ of this mixture was added to the wells of a 96-wells plate. After clotting at room temperature, the fibrin matrices were soaked with M199 supplemented with $10 \%$ (vol/vol) HS and 10\% (vol/vol) NBCS for 2 hours at $37^{\circ} \mathrm{C}$ to in-activate the thrombin. Confluent endothelial cells were split in a 1.25:1 ratio in M199 with 10\% HS, $10 \% \mathrm{NBCS}$ and penicillin/streptomycin, to provide a highly confluent monolayer on the fibrin matrices. After 24 hours culturing the endothelial cells were stimulated with $10 \mathrm{ng} / \mathrm{ml}$ bFGF (Pepro Tech EC, London, U.K.) and $10 \mathrm{ng} / \mathrm{ml}$ TNF $\alpha$ (gift of Dr. J. Travernier, Gent, Belgium). The medium was refreshed every 2-3 days. At the end of the culturing period the formation of tubular structures was analyzed by phase contrast microscopy. The total-length of the tubular structures was measured using a Nikon FXA microscope equipped with a monochrome CCD camera (MX5) connected to a computer with Optimas image analysis software.

\section{Enzyme-linked immunosorbent assays}

su-PA antigen determination was performed with the commercially available immunoassay kit su-PA EIA HS Taurus (Leiden, The Netherlands).

\section{Statistics}

All the results are presented as mean \pm SEM. Comparisons between $>2$ groups were made by 1-way ANOVA. Individual group comparisons of the means were done using a Student $t$ test. Differences were considered significant at $\mathrm{p}<0.05$.

\section{Results}

\section{CDI3 expression and inhibition of activity in endothelial cells}

The expression of CD13 protein and mRNA on hMVECs and HUVECs was confirmed by FACS analysis and RT-PCR (Figs. 1A, 1B). With real-time (light cycler) PCR, we calculated a minor, but not significant, increase in CD13 mRNA (expressed in Arbitrary Units) in hMVECs after treatment with bFGF/TNFa: $0.010 \pm 0.008$ for the control cells vs. $0.016 \pm 0.012$ for the $b F G F / T N F \alpha$ treated cells. However, no change was detected in CD13 antigen expression as measured with FACS analysis, after treatment of hMVECs with $\mathrm{bFGF/TNF} \alpha$ (not 


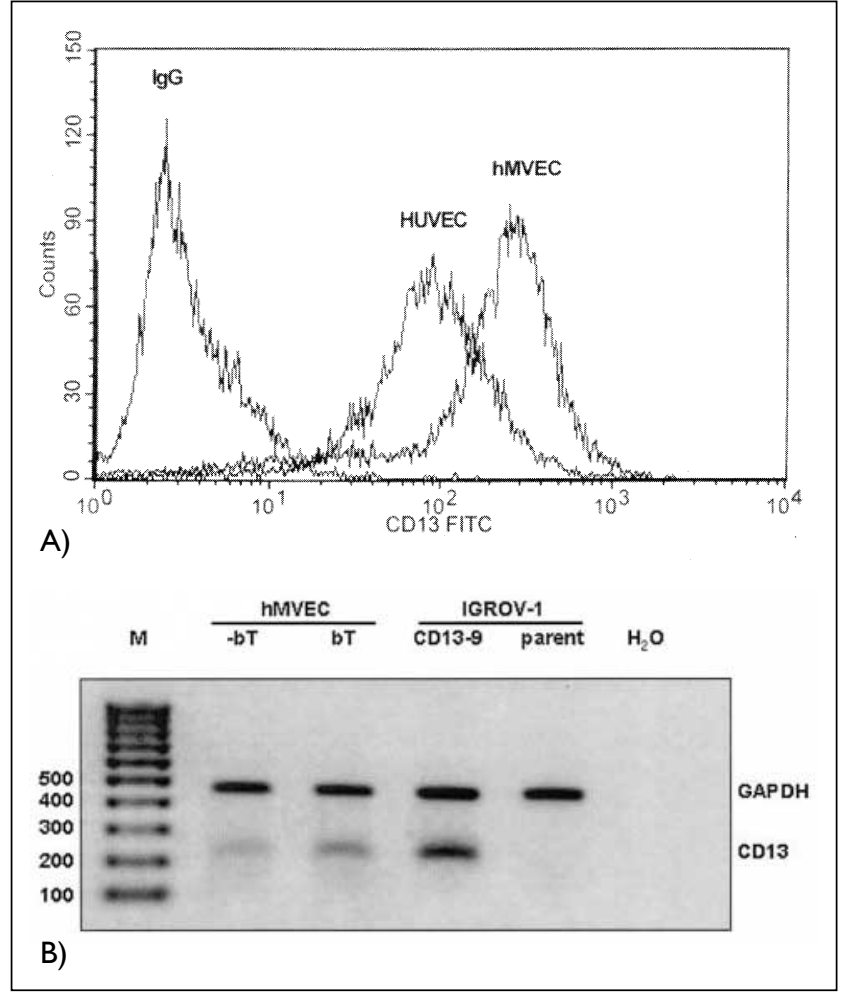

Figure I: CDI3 expression in HUVEC and hMVEC

The expression of CDI 3 protein and mRNA was confirmed for the HUVECs and hMVECs used in this study. A: HUVECs and hMVECs were grown under normal conditions until $80 \%$ confluence. The cells were harvested and CDI3 protein expression on the cell membrane was measured by FACS analysis. MouseIgG was used as a negative control. B:Total mRNA was isolated of hMVECs unstimulated (-bT) or stimulated (+bT) with bFGF $(I 0 \mathrm{ng} / \mathrm{ml})$ and TNF $\alpha(10 \mathrm{ng} / \mathrm{ml})(72 \mathrm{hrs})$ and analyzed with RT-PCR (36 cycles) for CD 3 expression. IGROV-I cells were used as positive control (CDI3-9, high overexpression of CDI3) or negative control (parent), ( $M=$ marker).

shown). We have used bestatin and the CD13-blocking antibody WM15 (23) as inhibitors of CD13 activity. N-terminal aminopeptidase activity in HT-1080 cell membrane preparations, which have a high membrane CD13 expression, were in-activated with $50 \%$ and $90 \%$ at $2.1 \mu \mathrm{M}$ and $15 \mu \mathrm{M}$ bestatin, respectively. The N-terminal aminopeptidase activity was blocked for $80 \%$ with WM15, which was achieved with $2.5 \mu \mathrm{g} / \mathrm{ml}$ (24). Possible growth inhibitory or toxic effects of bestatin and WM15 were excluded by MTT assay, which reflects the number of viable cells. Only high concentrations of bestatin had a growth inhibitory effect after prolonged incubation (72 h) $\left(\mathrm{IC}_{50}=340 \mu \mathrm{M}\right)$.

\section{Effect of bestatin and WMI5 on tube morphogenesis and endothelial invasion in Matrigel}

In agreement with the study of Bhagwat et al. (17), bestatin and WM15 inhibited VEGF-induced network formation of
HUVECs on Matrigel at relatively high concentrations (Figs. 2A, 2B). At low concentrations of bestatin $(1-10 \mu \mathrm{M})$ no effects were observed (data not shown). This suggests a contribution of CD13 to endothelial tube morphogenesis. Additionally, we examined the effect of CD13 inhibition on endothelial cell invasion using a Matrigel-coated filter (transwell system). At relatively high concentrations, bestatin inhibited the migration of endothelial cells through the Matrigel matrix, while the inhibition of cell migration by WM15 was not significant (Figs. 3A, $3 \mathrm{~B})$. Additionally, the migration assays were performed with hMVECs under identical conditions. Migration could only be quantified in some of the experiments because of the low rate of migration of VEGF-stimulated hMVEC in Matrigel. In two experiments, in which migration could be quantified in all conditions, the data were similar to those of HUVEC, i.e. no inhibition at $100 \mu \mathrm{M}$ bestatin $(2 \pm 2 \%)$ and $34 \pm 8 \%$ inhibition at $250 \mu \mathrm{M}$ bestatin.

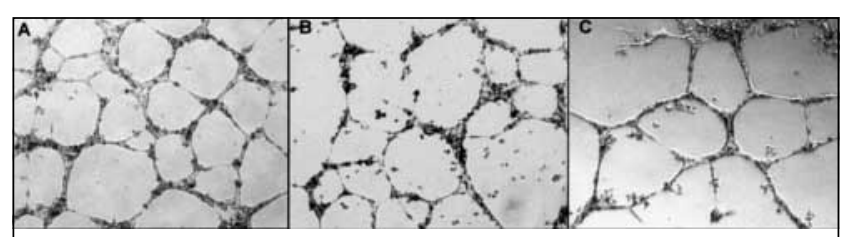

A)

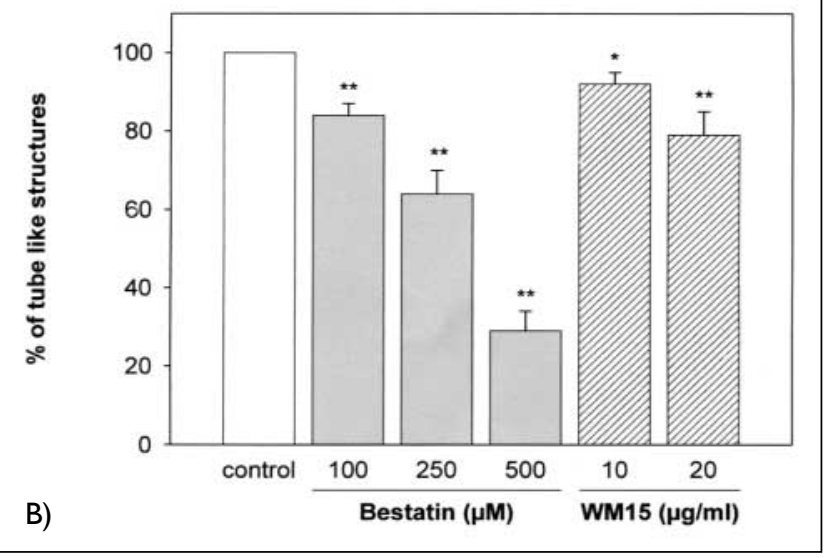

Figure 2: Bestatin and WMI5 reduce Morphogenesis of HUVEC on Matrigel

A: HUVECs were plated on top of a Matrigel in MI 99 supplemented with $0.5 \% \mathrm{FCS}$ and I $\mathrm{ng} / \mathrm{ml} \mathrm{VEGF} \mathrm{(A-C).} \mathrm{The} \mathrm{cells} \mathrm{were}$ incubated for 18 hours to form a tube-like-network. In the presence of $250 \mu \mathrm{M}$ bestatin (B) or $20 \mu \mathrm{g} / \mathrm{ml} \mathrm{WMI5}$ (C), network formation was reduced. Representative photographs (of at least 4 independent experiments) were taken 18 hours after stimulation.

B: HUVECs were plated on top of a Matrigel in MI 99 supplemented with $0.5 \%$ FCS and I ng/ml VEGF and the number of tube-like structures was counted after 18 hours. The data represent the percentage of tube like structures relative to the VEGF stimulated control cells (100\%=77 tubes/field). The results are the mean of at least 3 independent experiments \pm SEM $\left({ }^{*} \mathrm{p}<0.05\right.$, $\left.*_{*} p<0.01\right)$. A significant reduction in tube like structures was observed with $100-500 \mu M$ bestatin $(n=4, p=0.00 I)$ and with WMI 5 at $10 \mu g / m l ~(n=5, p=0.03)$ and $20 \mu g / m l(n=4, p=0.005)$. 


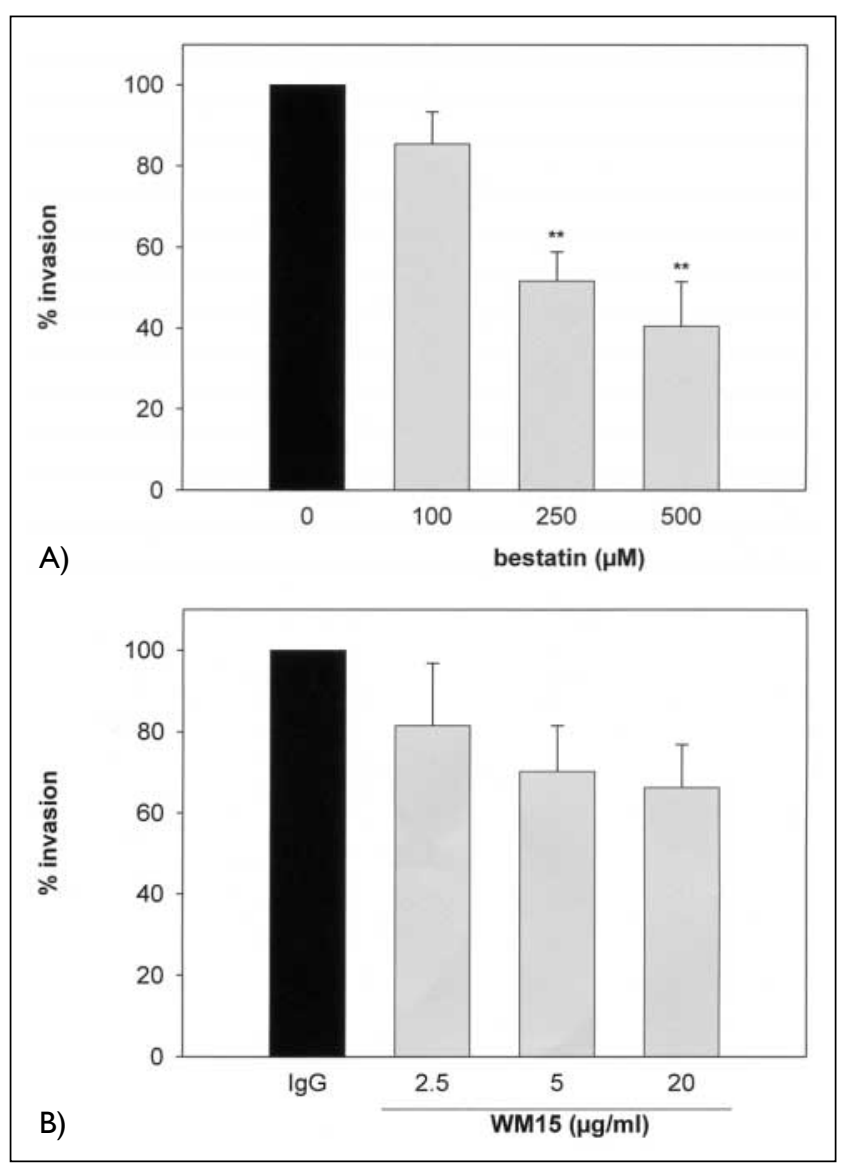

Figure 3: Invasion of HUVEC in Matrigel is inhibited by bestatin Invasion was performed in a transwell system coated with gelatin and a thin layer of Matrigel on top of the filter. HUVECs were added to the upper compartment in MI99 with $0.1 \%$ BSA Invasion was stimulated with $25 \mathrm{ng} / \mathrm{ml}$ VEGF for 18 hours with or without the CDI3 inhibitors. A: Bestatin inhibited invasion, which was significant at $250 \mu \mathrm{M}(n=4, p=0.007)$ and $500 \mu \mathrm{M}$ $(n=5, p=0.006)(* * p<0.0 I)$. B:WMI5 inhibited invasion compared with control $\operatorname{lgG}$, however not significantly.

\section{Effect of bestatin on capillary tube formation in a fibrin matrix}

Previously we have shown that hMVECs grown on top of a three-dimensional fibrin matrix form tube-like structures when stimulated with bFGF and TNF $\alpha$ (4). Unstimulated hMVECs remained as a monolayer and did not invade the fibrin-matrix, while the cells stimulated with $\mathrm{bFGF/TNF} \alpha$ formed capillary tubes. Surprisingly, bestatin enhanced $b F G F / T N F \alpha$-stimulated tube formation. Already at a low concentration $(8 \mu \mathrm{M}$, resulting in $80-90 \%$ inhibition of the total aminopeptidase activity), sprout formation was increased to $215 \pm 69 \%$ of the control. The effect of bestatin was concentration-dependent: $302 \pm 125 \%$ of the control at $50 \mu \mathrm{M}$ and $369 \pm 182 \%$ at $125 \mu \mathrm{M}$ (Figs. 4A, 4B). At $250 \mu \mathrm{M}$ bestatin, massive tube formation accompanied by matrix degradation was observed, which interfered with an accurate measurement of the extent of capillary tube formation.
Similar effects of bestatin were observed when the cells were stimulated with VEGF instead of bFGF (data not shown).

A direct binding of bestatin to the fibrin matrix or interference of this matrix with bestatin activity were excluded. In a control experiment, bestatin was incubated with a fibrin matrix under conditions similar to those used in the fibrin tube assay. The ability of bestatin to inhibit the aminopeptidase activity of endothelial cells remained $100 \%$ of the initial inhibitory activity at both 8 and $50 \mu \mathrm{M}$ bestatin.

\section{Role of CDI 3 activity in capillary-like tube formation in a fibrin matrix}

To study whether the pro-angiogenic effect of bestatin in a fibrin matrix was caused by inhibition of CD13 activity, we tested the effect of the anti-CD13 antibodies WM15 and MY7. WM15 enhanced the formation of tube-like structures by $22 \pm 9 \%$ and $50 \pm 56 \%$ at 2.5 and $10 \mu \mathrm{g} / \mathrm{ml} \mathrm{WM15}$ respectively, but this effect was not statistically significant (Fig. 4B). A second CD13 inhibitory antibody (MY7) did not affect tube formation ( $101 \%$ of control values at $10 \mu \mathrm{g} / \mathrm{ml})$. Subsequently, two other synthetic aminopeptidase inhibitors, amastatin and actinonin, were also tested on $\mathrm{bFGF/TNF} \alpha$ stimulated hMVECs. Amastatin and actinonin have an aminopeptidase inhibitory pattern very similar to bestatin $(13,25)$ but they are more potent (50\% inhibition of aminopeptidase activity at $2.1 \mu \mathrm{M}, 0.08 \mu \mathrm{M}$ and $0.07 \mu \mathrm{M}$ for bestatin, actinonin and amastatin respectively, as determined previously (24)). These aminopeptidase inhibitors enhanced the capillary-like tube formation, but to a lesser extent than bestatin. In a concentration range of 0.1 to $10 \mu \mathrm{M}$, actinonin and amastatin stimulated tube formation with $48 \%$ and 58\% maximally, however this did not reach significance. Since neither the inhibiting antibodies nor other (more active) synthetic aminopeptidase inhibitors were able to clearly reproduce the effect of bestatin in the fibrin matrix, the pro-angiogenic effect of bestatin appears to extend beyond the inhibitory effect on CD13 activity.

\section{Integrin expression on hMVECs is not affected by bestatin}

The in-growth of hMVECs into the matrix depends on proteases and cell matrix interactions. In particular, $\alpha_{v} \beta_{3^{-}}, \alpha_{v} \beta_{5^{-}}$and $\alpha_{1} \beta_{5}$-integrins play a role in the invasion of endothelial cells into the matrix $(26,27)$. When hMVECs were exposed to bestatin $(125 \mu \mathrm{M})$, no significant changes in the expression of the

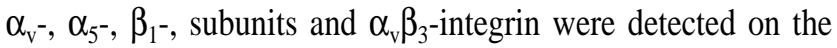
cells by FACS analysis (Fig. 5).

\section{The function of $u-P A$ and $u-P A R$ in the stimulatory effect of bestatin}

In agreement with our previous findings (28), tube-formation in a three-dimensional fibrin matrix depended on cell-bound u-PA activity and was largely inhibited by anti-u-PA antibodies (not 


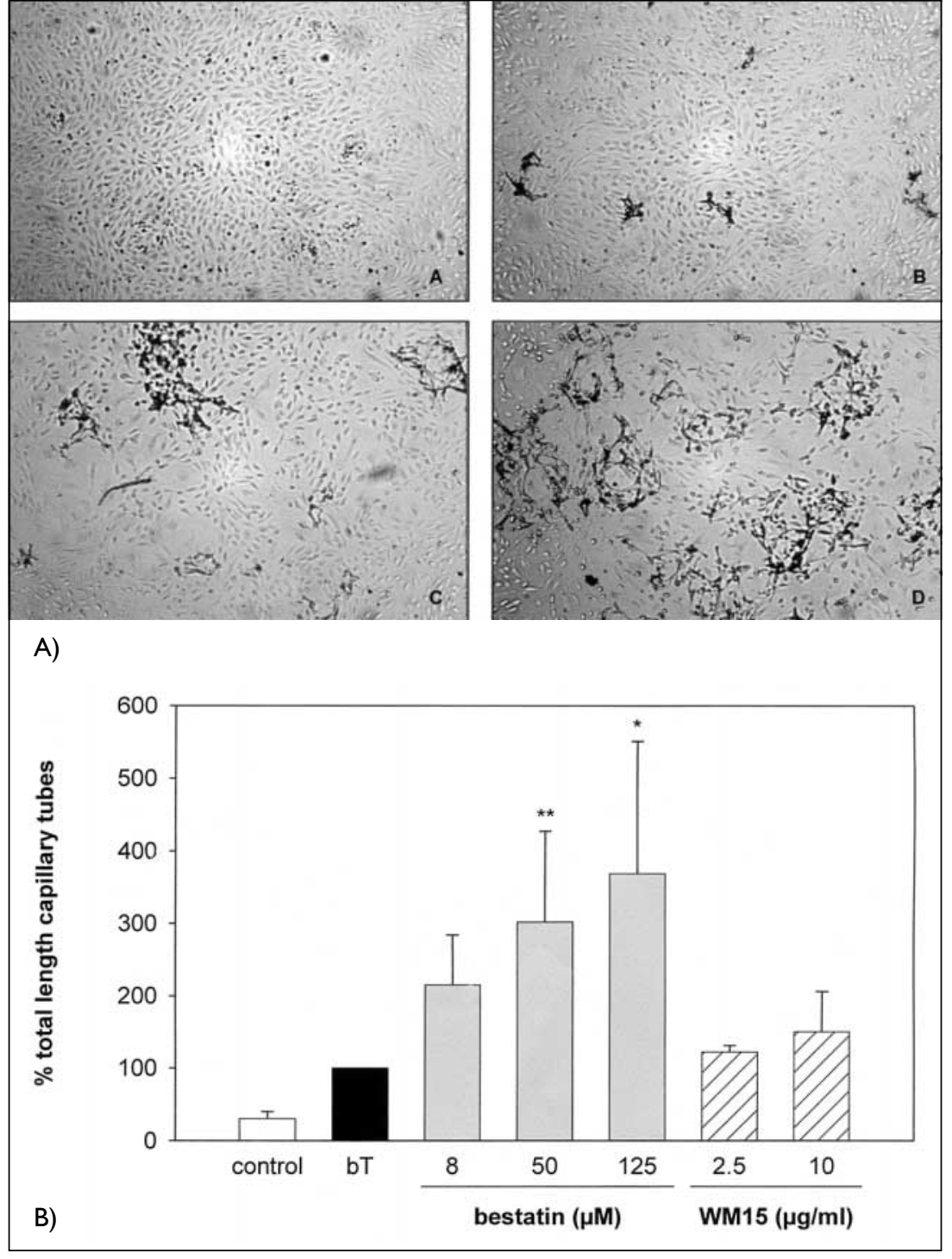

Figure 4: Tube formation in a fibrin gel is enhanced after incubation with bestatin and WMI5

A: hMVECs were cultured on top of a 3-dimentional fibrin matrix in M199 supplemented with $10 \%$ human serum and $10 \%$ NBCS without (A) or with bFGF $(10 \mathrm{ng} / \mathrm{ml})$ and TNF $\alpha(10 \mathrm{ng} / \mathrm{ml})(B-D)$. In the presence of bestatin $8 \mu \mathrm{M}(\mathrm{C})$ and $125 \mu \mathrm{M}(\mathrm{D})$, tube formation was enhanced. Representative photographs (of at least 4 independent experiments) were taken after 7 days of culture. B: hMVECs were cultured on top of a 3dimentional fibrin matrix in MI99 supplemented with $10 \%$ human serum and $10 \%$ NBCS without (control), or with bFGF $(10 \mathrm{ng} / \mathrm{ml})$ and TNF $\alpha(10 \mathrm{ng} / \mathrm{ml})(\mathrm{bT})$ in the presence of increasing amounts of bestatin or WMI5. After 7 days of culture, the total tube length $\left(\mathrm{mm} / \mathrm{cm}^{2}\right)$ was measured as described in materials and methods. The data were calculated as percentage of total tube length relative to the $\mathrm{bT}$ stimulated cells $\left(100 \%=184 \mathrm{~mm} / \mathrm{cm}^{2}\right)$. The data are the mean of at least 3 independent experiments \pm SEM $\left({ }^{*} p<0.05 ; *^{*} p<0.01\right)$. No significant enhancement of tube formation was seen for bestatin $8 \mu M(n=6, p=0.108)$ and WMI5 $(n=3$, $p=0.75$ ), while a significant increase was seen for bestatin $50 \mu M(n=5, p=0.008)$ and $125 \mu M(n=3, p=0.029)$. shown) and $\mathrm{H} 2$, an anti-u-PAR monoclonal antibody that inhibits u-PA binding to its receptor. $\mathrm{H} 2$ inhibited the tube formation with $78 \pm 3 \%$ (Fig. 6, no addition of bestatin). When $\mathrm{H} 2$ was added simultaneously with different concentrations of bestatin, tube formation was inhibited to a similar extent $(74 \pm 6 \%$ inhibition at $125 \mu \mathrm{M}$ bestatin) (Fig. 6). These experiments show that bestatin does not alter the relative contribution of a functional u-PA/u-PAR system to the formation of capillary-like tubular structures in a fibrin matrix.

To evaluate whether bestatin affected the availability of $\mathrm{u}-\mathrm{PA}, \mathrm{u}-\mathrm{PA}$ antigen was assessed in the conditional medium of tube forming cells. bFGF/TNF $\alpha$-stimulated hMVECs accumulated 3.8-fold more u-PA in the medium than non-stimulated cells $(n=3, p=0.004)$. However, no change in $u-P A$ accumulation was seen when the cells were treated with bestatin or WM15 (Fig. 7). Similarly, actinonin and amastatin did not change significantly u-PA accumulation by fibrin-invading hMVECs (data not shown).

\section{Discussion}

The angiogenic switch in tumors is thought to be an essential step of a tumor in its malignant progression. The recognition of the important role of angiogenesis in tumor growth has now led to intense interest in the identification of drugs with anti-angiogenic properties as potential anti-tumor therapeutics. Recently, the synthetic aminopeptidase inhibitor bestatin has been reported to have anti-angiogenic properties in several in vitro and in vivo models $(17,18)$. Those studies showed evidence that the bestatin effects were the result of inhibition of CD13 activity $(17,18,20)$. In this report we describe that bestatin enhances capillary-like tube formation in a fibrin matrix already at very low concentrations. Therefore, we are the first to report proangiogenic effects of bestatin and of aminopeptidase inhibitors in general. We could not identify a direct effect of bestatin on $\mathrm{u}-\mathrm{PA} / \mathrm{u}-\mathrm{PAR}$ activity, which is important for the magnitude of 
Figure 5: Integrin expression on hMVECs is not affected by bestatin

hMVECs were grown under standard conditions until $50-80 \%$ confluence, and were then cultured for 24 hours in MI 99 supplemented with $10 \% \mathrm{HS}, 10 \%$ NBCS. Subsequently, the cells were stimulated with bFGF $(10 \mathrm{ng} / \mathrm{ml})$ and TNF $\alpha(10 \mathrm{ng} / \mathrm{ml})$ without (closed bars) or with $125 \mu \mathrm{M}$ Bestatin (hatched bars) for 72 hours. Afterwards, integrin expression was measured by FACS analysis. The data are presented as mean fluorescence \pm SEM $(n=2)$. No substantial changes were observed in integrin expression after treatment with bestatin.

Figure 6: u-PAR activity is not directly affected by bestatin

hMVECs were cultured on top of a 3-dimentional fibrin matrix in MI99 supplemented with $10 \%$ human serum and $10 \%$ NBCS without (control (-bT)(closed bar)), or with bFGF (I0 ng/ml) and TNF $\alpha(10 \mathrm{ng} / \mathrm{ml})$. bT stimulated cells were simultaneously treated with increasing amounts of bestatin alone (black dots) or in combination with $\mathrm{H} 2$ $(5 \mu \mathrm{g} / \mathrm{ml})$ (open dots). After 7 days of culture, the total tube length $\left(\mathrm{mm} / \mathrm{cm}^{2}\right)$ was measured as described in materials and methods. The data are calculated as percentage of total tube length relative to the bT stimulated control cells $\left(100 \%=87.55 \mathrm{~mm} / \mathrm{cm}^{2}\right)$. Data are expressed as mean \pm SEM $(n=2)$. Total tube length was reduced with $\mathrm{H} 2$; however, the relative inhibition of $\mathrm{H} 2$ was not affected by addition of bestatin.

Figure 7: u-PA accumulation is not affected by bestatin

hMVECs were cultured on top of a 3-dimentional fibrin matrix in MI99 supplemented with $10 \%$ human serum and $10 \%$ NBCS without (control), or with bFGF $(10 \mathrm{ng} / \mathrm{ml})$ and TNF $\alpha(10 \mathrm{ng} / \mathrm{ml})(\mathrm{bT})$ in the presence of increasing amounts of bestatin or WMI5. At day 2 and day 5 , the medium of the cells was collected and the u-PA accumulation from day 0 to day 5 was measured by ELISA. The data are calculated as percentage of u-PA accumulation relative to the bT stimulated cells $(100 \%=42 \mathrm{ng} / \mathrm{ml})$. Data are expressed as the mean \pm SEM of at least 2 independent experiments $(* * p>0.01)$. No changes were observed with bestatin $(n=3, p=0.38)$ or WMI5 $(n=2, p=0.16)$.
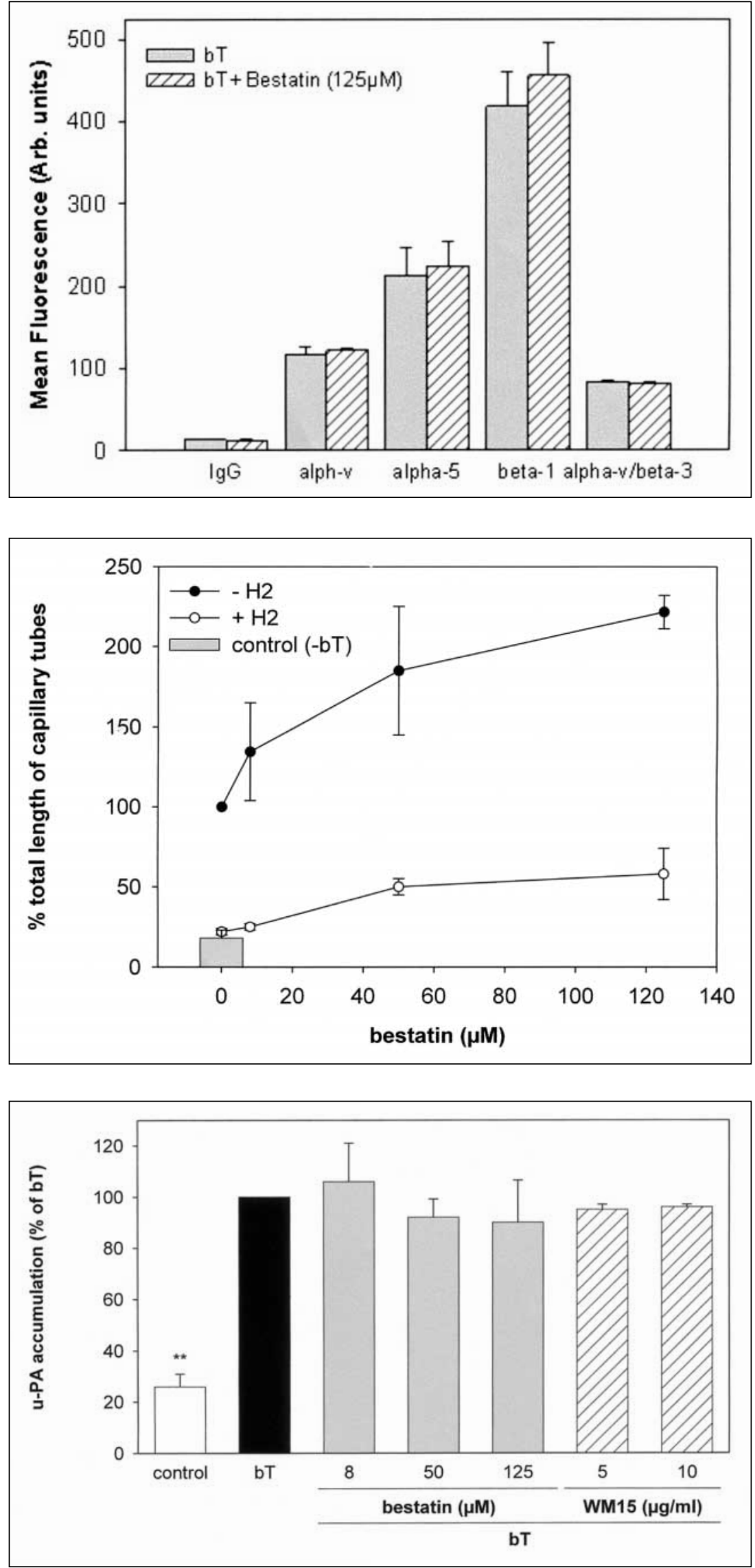
the total tube formation. Our results demonstrate that the relative involvement of $\mathrm{u}-\mathrm{PA} / \mathrm{u}-\mathrm{PAR}$ in tube formation was not altered by bestatin.

The endothelial cells used in our study expressed CD13. This is probably due to the fact that ECGF was present in the culture medium, which contains FGF-1 (acidic FGF) as a major growth factor. It is known that $\mathrm{bFGF}$ increases CD13 expression in endothelial cells (19). In accordance with previous studies (17), we observed an anti-angiogenic effect of bestatin on endothelial cell morphogenesis and endothelial cell invasion in a Matrigel matrix. These effects were established with relatively high concentrations of bestatin. In agreement with Bhagwat et al. (17), our data with anti-CD13 antibodies also show a contribution of CD13 in endothelial cell morphogenesis. However, these effects were less pronounced when compared to the bestatin induced effects, suggesting that bestatin may also act on other peptidases in this assay.

Interestingly, a reverse effect of bestatin on endothelial invasion in a fibrin matrix was established in this study. Already at low concentrations of bestatin capillary-like tube formation was enhanced, while at high concentrations a massive degradation of the fibrin matrix occurred. In view of the low concentration at which bestatin is active in the fibrin matrix and the slow membrane passage properties of bestatin (14), it is likely that its primary target is a plasma membrane-expressed aminopeptidase. The limited activity of incubation with anti-CD13 antibodies and other aminopeptidase inhibitors in the fibrin matrix suggested that the inhibition of the proteolytic activity of an aminopeptidase other than $\mathrm{CD} 13$ is a major contributor to the pro-angiogenic effect of bestatin. Considering the low concentration at which bestatin is effective, possible targets are the other plasma membrane-associated aminopeptidases, such as aminopeptidase B or cystinyl aminopeptidase (14). The direct or indirect involvements of these peptidases in angiogenesis have to be further evaluated.

The pro-angiogenic effect of bestatin appears to depend on the matrix environment because we found no effect of these low concentrations of bestatin, stimulatory or inhibitory, on tube formation on Matrigel (not shown). This suggests that bestatin acts on (an) aminopeptidase(s) that modify proteins related to the interaction of endothelial cells with this matrix or on (an) aminopeptidase(s) that act on structural proteins of the matrix itself. The interaction of hMVECs with a fibrin matrix is largely dependent on integrins. In particular the $\alpha_{v} \beta_{3^{-}}, \alpha_{v} \beta_{5^{-}}, \alpha_{5} \beta_{1^{-}}$-integrins are important for the adhesion to, and migration and invasion into the fibrin matrix (our own observations). No significant changes were observed in the expressions of the $\alpha_{v} \beta_{3}$-integrin and the $\alpha_{v^{-}}, \alpha_{5^{-}}$and $\beta_{1}$-subunits on the membrane of bestatintreated hMVECs. Although a change in the activity of one of these integrins cannot be excluded yet, we did not find direct evidence for this. In a wound-assay, bestatin did not affect the migration of HUVECs on fibronectin at concentrations up to $100 \mu \mathrm{M}$ (data not shown). This is an indication that bestatin does not change the activity of the integrins, however, more detailed studies on integrin signaling are needed to resolve this issue.

The apparent contradiction between anti-angiogenic and pro-angiogenic activities of a protease inhibitor has been reported before. The broadly acting MMP inhibitor BB94 enhanced capillary-like tube formation of hMVECs on top of a fibrin matrix by protecting the u-PAR from degradation by MMP- 12 (9). u-PA bound to its receptor u-PAR represents a pivotal proteinase involved in the formation of capillary-like tubes in a fibrin matrix. Prevention of MMP-dependent u-PAR degradation by BB94 enhanced tube-formation. Such a mechanism did not underlie the stimulatory effect of bestatin. The relative inhibition of the u-PA binding to u-PAR by $\mathrm{H} 2$ was similar with or without bestatin (70-80\% inhibition in both conditions), indicating that bestatin does not directly affect a) the activity of the $\mathrm{u}-\mathrm{PAR}$ or $\mathrm{b}$ ) the binding of u-PA to u-PAR. However, the overall formation of tube-like structures was reduced in the presence of $\mathrm{H} 2$, therefore, these results strongly suggest that u-PA and u-PAR are essential components of the mechanism by which bestatin enhances $\mathrm{bFGF/TNF} \alpha$-stimulated capillary-like tube formation in a fibrin gel.

Because there was a considerable degradation of the fibrin matrix at high concentrations of bestatin, it is possible that bestatin affects the production of u-PA. However, no change in the accumulation of $\mathrm{u}$-PA antigen was observed. A change in the intracellular concentration of u-PA by bestatin is highly unlikely, since the intracellular concentrations of u-PA in endothelial cells are relatively low. Moreover, stimulation of endothelial cells with bFGF and TNF $\alpha$ hardly affects the intracellular concentrations of $\mathrm{u}-\mathrm{PA}$, while the accumulation in the medium is strongly increased (29). Incubation with BB94, which enhanced the number of active u-PAR on the endothelial cells, substantially decreased u-PA antigen accumulation in the medium, indicating once more that the pro-angiogenic mechanism of bestatin is not similar to that of BB94 (9). Although we did not observe a change in the amount of u-PA, we cannot yet exclude a change in u-PA activity. u-PA is present in the medium as an inactive single chain precursor (scu-PA) and can be cleaved by plasmin and other proteases into active two-chain u-PA (tcu-PA) $(30,31)$ or by thrombin into in-active tcu-PA, called tcu-PA/T (32). We cannot exclude the possibility that the activity of one or more aminopeptidases may inhibit the activation of u-PA and that bestatin prevents this inactivation.

Besides matrix adhesion proteins and matrix degradation proteins, the structure of the matrix itself is also essential for the angiogenic potential of the endothelial cells $(3,33,34)$. Therefore, an additional explanation may be sought in the modulation of the fibrin structure by bestatin. Recently, it was reported that several factors affect the rigidity of the fibrin matrix, thereby altering the sensitivity of fibrin to proteases. Consequently, this may substantially affect the number of capillary-like tubes as well as the stability of the tubes (35). Moreover, the carboxy- 
peptidase $B$ was shown to retain the rigidity of the fibrin matrix (36). Although bestatin is not able to inhibit the activity of carboxypeptidase B, it remains possible that N-terminal aminopeptidases that can be inhibited in activity by bestatin can modify the properties and stability of the fibrin matrix.

In conclusion, we have provided evidence for a novel effect of bestatin on in vitro angiogenesis. These findings should be taken into account when evaluating the antitumor effects of bestatin because a fibrinous exudate is often the primary matrix around tumors, and it facilitates endothelial invasion (2). Our results may also add to the elucidation of the numerous interactions between the different proteolytic systems. Adequate knowledge of the role of aminopeptidases and their inhibitors in angiogenesis is needed for proper understanding of the potential of bestatin and related agents as anti-angiogenic and anti-tumor agent.

\section{Abbreviations}

VEGF, vascular endothelial growth factor; u-PA, urokinase-type plasminogen activator; u-PAR, urokinase-type plasminogen activator receptor; MMP, matrix metalloproteinase; MT1-MMP, membrane type-1 matrix metalloproteinase; bFGF, basic fibroblast growth factor; hMVEC, human foreskin microvascular endothelial cell; HS, human serum; NBCS, new born calf serum; HUVEC, human umbilical vein endothelial cell; TNF $\alpha$, tumor necrosis factor- $\alpha$; su-PA, soluble u-PA; BB94, batimastat; scu-PA, single-chain u-PA; tcu-PA, two-chain u-PA; bT, bFGF and TNF $\alpha$

\section{References}

1. Carmeliet P, Jain RK. Angiogenesis in cancer and other diseases. Nature 2000; 407: 249-57.

2. Dvorak HF. Tumors: wounds that do not heal Similarities between tumor stroma generation and wound healing. N Engl J Med 1986; 315 : 1650-9.

3. van Hinsbergh VW, Koolwijk P, Hanemaaijer R. Role of fibrin and plasminogen activators in repair-associated angiogenesis: in vitro studies with human endothelial cells. EXS 1997; 79: 391-411.

4. Koolwijk P, van Erck MG, de Vree WJ, et al.. Cooperative effect of TNFalpha, bFGF, and VEGF on the formation of tubular structures of human microvascular endothelial cells in a fibrin matrix. Role of urokinase activity. J Cell Biol 1996; 132: 1177-88.

5. Pepper MS, Belin D, Montesano R, et al.. Transforming growth factor-beta 1 modulates basic fibroblast growth factor-induced proteolytic and angiogenic properties of endothelial cells in vitro. J Cell Biol 1990; 111: 743-55.

6. Pepper MS. Role of the matrix metalloproteinase and plasminogen activator-plasmin systems in angiogenesis. Arterioscler Thromb Vas Biol 2001; 21: 1104-17.

7. Murphy G, Stanton H, Cowell S, et al. Mechanisms for pro matrix metalloproteinase activation. APMIS 1999; 107: 38-44.

8. Andolfo A, English WR, Resnati M, et al. Metalloproteases cleave the urokinase-type plasminogen activator receptor in the D1-D2 linker region and expose epitopes not present in the intact soluble receptor. Thromb Haemost 2002; 88: 298-306.

9. Koolwijk P, Sidenius N, Peters E, et al.. Proteolysis of the urokinase-type plasminogen activator receptor by metalloproteinase-12: implication for angiogenesis in fibrin matrices. Blood 2001; 97: 3123-31.

10. Collen A, Hanemaaijer R, Lupu F, et al.. Membrane-type matrix metalloproteinase mediated angiogenesis in a fibrin-collagen matrix. Blood 2003; 101: 1810-7.

11. Hiraoka N, Allen E, Apel IJ, et al.. Matrix metalloproteinases regulate neovascularization by acting as pericellular fibrinolysins. Cell 1998; 95: 365-77.

12. Lafleur MA, Handsley MM, Knauper V, et al.. Endothelial tubulogenesis within fibrin gels specifically requires the activity of membranetype-matrix metalloproteinases (MT-MMPs). J Cell Sci 2002; 115: 3427-38
13. Umezawa $\mathrm{H}$, Aoyagi $\mathrm{T}$, Suda $\mathrm{H}$, et al.. Bestatin, an inhibitor of aminopeptidase B, produced by actinomycetes. J Antibiot (Tokyo) 1976; 29: 97-9.

14. Scornik OA, Botbol V. Bestatin as an experimental tool in mammals. Current Drug Metabolism 2002; 2: 67-85.

15. Ota K. Review of ubenimex (Bestatin): clinical research. Biomed Pharmacother 1991; 45: 5560.

16. Ota K, Uzuka Y. Clinical trials of bestatin for leukemia and solid tumors. Biotherapy 1992; 4: 205-14.

17. Bhagwat SV, Lahdenranta J, Giordano R, et al.. CD13/APN is activated by angiogenic signals and is essential for capillary tube formation. Blood 2001; 97: 652-9.

18. Pasqualini R, Koivunen E, Kain R, et al.. Aminopeptidase $\mathrm{N}$ is a receptor for tumor-homing peptides and a target for inhibiting angiogenesis. Cancer Res 2000; 60: 722-7.

19. Bhagwat SV, Petrovic N, Okamoto Y, et al. The angiogenic regulator CD13/APN is a transcriptional target of Ras signaling pathways in endothelial morphogenesis. Blood 2003; 101: 1818-26.

20. Hashida H, Takabayashi A, Kanai M, et al.. Aminopeptidase $\mathrm{N}$ is involved in cell motility and angiogenesis: its clinical significance in human colon cancer. Gastroenterology 2002; 122: $376-86$

21. van Hensbergen Y, Broxterman HJ, Hanemaaijer R, et al.. Soluble aminopeptidase N/CD13 in malignant and nonmalignant effusions and intratumoral fluid. Clin Cancer Res 2002; 8: 3747-54.

22. van Hinsbergh VWM, Draijer R. Culture and characterization of human endothelial cells. In: Oxford University Press. Shaw AJ 1996; 87-110.

23. Favaloro EJ. CD-13 ('gp150'; aminopeptidase$\mathrm{N})$ : co-expression on endothelial and haemopoietic cells with conservation of functional activity. Immunol Cell Biol 1991; 69: 253-60.

24. van Hensbergen Y, Broxterman HJ, Elderkamp YW, et al.. A doxorubicin-CNGRC-peptide conjugate with prodrug properties. Biochem Pharmacol 2002; 63: 897-908.

25. Xu Y, Lai LT, Gabrilove JL, et al.. Antitumor activity of actinonin in vitro and in vivo. Clin Cancer Res 1998; 4: 171-6.

26. Gao B, Saba TM, Tsan MF. Role of alpha(v)beta(3)-integrin in TNF-alpha-induced endothelial cell migration. Am J Physiol Cell Physiol 2002; 283: 1196-1205.

27. Rüegg C, Dormond O, Foletti A. Suppression of tumor angiogenesis through the inhibition of integrin function and signaling in endothelial cells: which side to target? Endothelium 2002; 9: 151-60.

28. Kroon ME, Koolwijk P, van Goor H, et al.. Role and localization of urokinase receptor in the formation of new microvascular structures in fibrin matrices. Am J Pathol 1999; 154: $1731-42$

29. van Hinsbergh VW, van den Berg EA, Fiers W, et al.. Tumor necrosis factor induces the production of urokinase-type plasminogen activator by human endothelial cells. Blood 1990; 75: 1991-8.

30. Emeis JJ, Verheijen JH, Ronday HK, et al.. Progress in clinical fibrinolysis. Fibrinolysis Poteolysis 1997; 11: 67-84.

31. Takeuchi T, Harris JL, Huang W, et al.. Cellular localization of membrane-type serine protease 1 and identification of protease-activated receptor-2 and single-chain urokinase-type plasminogen activator as substrates. J Biol Chem 2000; 275: 26333-42.

32. Ichinose A, Fujikawa K, Suyama T. The activation of pro-urokinase by plasma kallikrein and its inactivation by thrombin. J Biol Chem 1986; 261: 3486-9.

33. Collen A, Smorenburg SM, Peters E, et al.. Unfractionated and low molecular weight heparin affect fibrin structure and angiogenesis in vitro. Cancer Res 2000; 60: 6196-6200.

34. Collen A, Maas A, Kooistra T, et al.. Aberrant fibrin formation and cross-linking of fibrinogen Nieuwegein, a variant with a shortened Aalphachain, alters endothelial capillary tube formation. Blood 2001; 97: 973-80.

35. Collen A, Koolwijk P, Kroon ME, et al.. Influence of fibrin structure on the formation and maintenance of capillary-like tubules by human microvascular endothelial cells. Angiogenesis 1998; 2: 153-65.

36. Bajzar L, Manuel R, Nesheim ME. Purification and characterization of TAFI, a thrombin-activable fibrinolysis inhibitor. J Biol Chem 1995; 270: $14477-84$ 